\title{
Solar Panel Efficacy vs. Altitude in an Urban City Environment
}

\section{Wiaam Yasser Elkhatib, Students for the Exploration and Development of Space (SEDS) IUPUI Chapter}

Wiaam Y. Elkhatib is a biomedical engineering student and aspiring physician-engineer at Purdue University, Indianapolis. Wiaam's research with the Richard G. Lugar Center for Renewable Energy quantitates photovoltaic efficacy in urban environments, while as an intern through the Indiana University School of Medicine, he evaluates the musculoskeletal effects of various chronic kidney disease interventions. An avid campus educator and leader, Wiaam serves as president of both the Students for the Exploration and Development of Space (SEDS) and Biomedical Engineering Society (BMES) chapters. He is also an academic success mentor who facilitates incoming university students in achieving educational fulfillment while encouraging involvement with undergraduate campus research.

\section{Prof. Peter J. Schubert, Indiana University Purdue University, Indianapolis}

Schubert is a Professor of Electrical and Computer Engineering and serves as the Director of the Richard G. Lugar Center for Renewable Energy (www.lugarenergycenter.org) and the faculty advisor for Students for the Exploration and Development of Space (SEDS) at IUPUI. He holds 40 US Patents, a Professional Engineering License (Illinois), and has published over 90 technical papers and book chapters. Schubert has managed research projects from USDA, NASA, DOE, and DoD.

\section{Mr. Steven Anthony Zusack, Indiana University Purdue University Indianapolis}

Mechanical Engineering student. Current research includes renewable energy in the form of ethanol fuel cells and solar power. Aspirations of pursuing $\mathrm{PhD}$ in the field of Aerospace Engineering with a focus on Spacecraft Design.

Mrs. Emily Carol Rosales, Indiana University-Purdue University Indianapolis

Emily Rosales is an undergraduate student at Indiana University-Purdue University Indianapolis, working on her bachelor's degree in Energy Engineering. She is actively involved in student organizations including Students for the Exploration and Development of Space, The Student Sustainability Council, and The Society of Women Engineers and has also been named to the dean's list for the Purdue School of Engineering and Technology. She graduated high school in Spring Lake Park, Minnesota and currently lives in Brownsburg, Indiana with her husband and two children.

\section{Mr. Austin C. Stanforth MS, IUPUI}

Austin C. Stanforth is a Graduate Research Assistant with the Institute for Research on Social Issues (IRSI) and Department of Geography at Indiana University Purdue University Indianapolis (IUPUI). He is a Doctoral Candidate in the Applied Earth Sciences program at IUPUI and holds a Master's of Science degree in Geographic Information Science (MS GIS) from Indiana University. His research is focused on geospatial analysis of socioeconomic and environmental variables which are statistically identified as vulnerability indicators of heat-related illness, and improving spatially specific heat warning systems. His research interests are in remote sensing, image analysis, and geographic information sciences with particular attention paid to environmental sciences and anthropogenic interactions. 


\title{
Solar Panel Efficacy vs. Altitude in an Urban Environment
}

\begin{abstract}
In light of current issues of global warming, pollution, and fossil fuel depletion, alternative and renewable energy sources are increasing in desirability. Among these, solar energy is a popular option. However, it is hypothesized that particulate pollution in urban atmospheres limits photovoltaic (PV) efficacy both in accumulated grime and also in altitude via sunlight attenuation. The objective of this study is to measure photovoltaic power output near solar noon at multiple heights within a city environment to determine the influence of altitude on power output. Building rooftops between 200 and 800 feet were sampled simultaneously with a ground level control within a broad university courtyard. Days having no cloud cover were preferentially chosen. Other factors to consider include the "urban heat island" effect and water vapor in the air, so meteorological parameters were measured simultaneously to reduce confounding errors. Multiple repeated tests were conducted to increase confidence, especially since the effect was anticipated to be small in magnitude. Additionally, students affiliated with the project completed surveys to assess how their involvement impacted their learning of experimental design and procedures. Students who chose not to participate were also surveyed to provide a control group. Comparisons in the data are drawn on a power to ambient light ratio to minimize bias between the PV panels used for testing.

Preliminary analysis indicates the effect of altitude is minimal within the parameters of this study. Analysis of our data did not significantly demonstrate an improvement in solar productivity at increased altitudes. However, the rigorous test methodology developed provides a means for quantitative analysis in cities with greater levels of pollution relative to the city tested. The survey of students indicated a positive correlation between participation in the project and the amount students felt they learned during the process.
\end{abstract}

\section{Introduction}

Many undergraduate lab courses in the science and engineering fields are designed to introduce students to fundamental experimental techniques through guided laboratory tours, but may not develop a student's ability to design original experiments. Therefore, this project was undertaken with the intention of giving students the opportunity to design, implement, and analyze an original experiment. Towards this goal, students initiated two related sub-projects; the first was to design and implement an experiment on altitude's impact on solar panels, and secondly to assess student learning, motivation, and appreciation of experimental design and testing based on their level of participation.

The experimental portion of the project was conducted with an interest in identifying available space for solar panel installment within urban settings for improved renewable energy practices. Solar farms built in unpopulated areas have gained popularity for local purposes due to its clean and renewable energy classification ${ }^{1}$. The question becomes whether unused space on top of buildings provide an alternative location for urban solar power production. Therefore, students designed a procedure to compare the available sunlight (measured in lux) and solar power generated (Watts) at ground level and atop multiple buildings in an urban area. The results 
were then tabulated and analyzed by students to complete their experimental design and analysis experience. The students involved also gained educational research experience, such as familiarity with the scientific method, experimental design, protocol development, data analysis, scientific literature research, and technical composition. The hope was this experience would improve the students' interest in educational research, enhance their knowledge and abilities to conduct such research, and potentially lead to higher education aspirations within STEM career opportunities.

A post assessment of student learning was conducted via survey responses to explore how experience and knowledge of experimental proceedings was impacted by a student's attitude towards and desire to participate in original experimental studies. This project works to fill the gap in the student academic experience and better understand what kind of students become active in group laboratory projects.

\section{Background}

Solar energy can be most efficiently harnessed in areas near the equator or those which otherwise receive large amounts of insolation, of which the Midwestern city of Indianapolis, Indiana is a potential candidate within certain parameter considerations ${ }^{2}$. Within the context of this experiment, those variable considerations included not only altitude, but air-borne particulate matter, meteorological conditions, and temperature which may be affected by the urban heat island effect ${ }^{4}$. Weather consideration shows that an altitude of 12.4 miles (20 kilometers) would be optimal for solar power collection within the earth's biosphere. The effects on solar panel output at lower altitudes, while not nearly as noticeable, are not well-known and could prove to be useful. According to previous experiments on solar panel efficacy conducted at the same sunlight intensity and time of day, a further power increase of 7-12\% is possible to be observed due to placement of solar panels at a particular height of 90 feet $(27.4 \mathrm{~m})$ above ground level ${ }^{3}$.

Another parameter to possibly consider is solar panel sensitivity to temperature with respect to material changes in silicon components ${ }^{5}$. Urban heat islands can initiate increased air conditioning costs, large particulate matter byproducts, and $\mathrm{CO}_{2}$ emissions, especially if this power comes from traditional energy generation sources such as coal, which in turn can reduce solar panel efficiency. While such effects are certainly conceivable within the city tested, their results were comparable to the error magnitude. The degree to which particulate matter impacts the solar panel is dependent on the thickness, density, and nature of the particulates adhering to the surface as shown by previous literature ${ }^{6}$. Humidity is also known to impact insolation to varying degrees ${ }^{7}$.

\section{Methods}

Experiment: Experimental locations were conducted on the rooftops of various high altitude buildings in the downtown Indianapolis area (39 degrees, 46 minutes north latitude) around solar noon. Clear and sunny days were chosen preferentially. Control experiments were conducted at a consistent ground level location with all hardware units to ensure equipment functionality and baselines for data normalization. Cardboard apparatuses were constructed to transport and house the 5-piece experimental equipment set used during this project to measure sunlight, temperature, barometric pressure, altitude, voltage, and current. The equipment used in this experiment consisted of a 12V Moultrie Universal Solar Panel (dimensions 8.4 x 5.4 x 1.6 
inches), an Elekcity® Digital LCD Multimeter, a Dr. Meter Digital Illuminance Meter with LCD screen (Model LX1010B), and an all-in-one Atech Navigator Digital Altimeter (altimeter, barometer, thermometer, hygrometer, and weather forecast). The solar panel was placed flat on top of the apparatus directly next to the light-collecting dome of the lux meter to eliminate confounding impacts associated with setting the devices directly on the ground. A small air vent was also cut out underneath to prevent any trapped heat. The additional equipment to measure lux, pressure, temperature, and elevation were placed within the shade of the apparatus to reduce impact of heat from the sun on their measurements. Batteries for all devices were checked prior to usage to ensure optimal function.

On the day of an experiment, both the ground/control and experimental teams convened at the control location where equipment was removed from padded, protective storage containers, thoroughly cleaned, calibrated, and checked for damage. The apparatus in its entirety was positioned flat on the ground with the solar panel and light-collecting dome of the lux meter facing parallel to the sky. An initial control test was then run at the control ground-level ( $715 \mathrm{ft}$ above sea level) site simultaneously for each apparatus placed within the same vicinity, recording measurements of sunlight, temperature, barometric pressure, altitude, voltage, and current at 60 second cycle intervals for a total recording time of 8 minutes. Students were instructed to stay away from large objects, and to sit to the north of the solar panel and the lux meter lens to prevent creating any artificial shadows. After the 8 minute mark, each group of students quickly took their assigned apparatus to a designated skyscraper rooftop while one student group remained with their apparatus at the ground/control site.

Communication between students was now entirely conducted via a merged cellular phone call, with stopwatches used at each test site as an added precaution. Once all students were in position, the ground/control group initiated the same test as before and both the ground/control apparatus and all high-altitude skyscraper rooftop apparatuses had their readings simultaneously recorded at another set of 60 second cycle intervals for 8 minutes. Following the experiment, a second control test back at the ground/control site was run for the first few tests, but was later discontinued due to the apparent lack of interference on equipment calibration during transport. Data was then entered and analyzed using Microsoft Excel software for all calculations.

Student Outcomes: In order to evaluate the effects this project had on students involved, non-identifying online surveys were conducted inquiring about various aspects of their experience. Two separate surveys are administered, instructing the recipients of which survey to take based on whether or not they had participated in the project. Those who had not participated were invited to respond to questions tailored to them, primarily investigating why they chose not to engage in the project, and including questions which could be compared to outcomes from those who did participate. Participants were asked, regardless of level of involvement, questions relating to what they gained from the experience and overall impressions/conclusions. All questions asked had multiple-choice answers, many with the option of selecting from a range of values where appropriate. The survey was conducted online to ensure the maximum number of participants involved. Questions were chosen based on feedback from members of the project team and from the faculty mentor of the group.

\section{Results}


Experiment: Due to the complexity of the project, several variables were recorded for analysis in the research. With limited variation in altitudes being reached and multiple potential variables affecting the power output of the solar cells, the group attempts to counteract these unknowns by collecting as much data as possible. The variables of focus will be lux, power, and temperature, as these are seen to be most impactful on solar irradiation (lux and temperature) and the output itself (power). Power is a calculated reading based on the recorded current and voltage. Variables not presented in this document are barometric pressure, wind speed, and humidity, as they did not appear to vary in any discernable amount. The altitude readings presented here refer to the different locations at varying altitudes. Control readings refer to the corresponding readings taken at ground level. To summarize the data, all readings from each altitude are averaged along with the corresponding control readings; meaning only control readings that were taken at the same time at the specific altitude are compared. The error bars represent the average of maximum and minimum readings from the location it appears with.

Total average power readings for all experiments per altitude can be seen in Table 1 below.

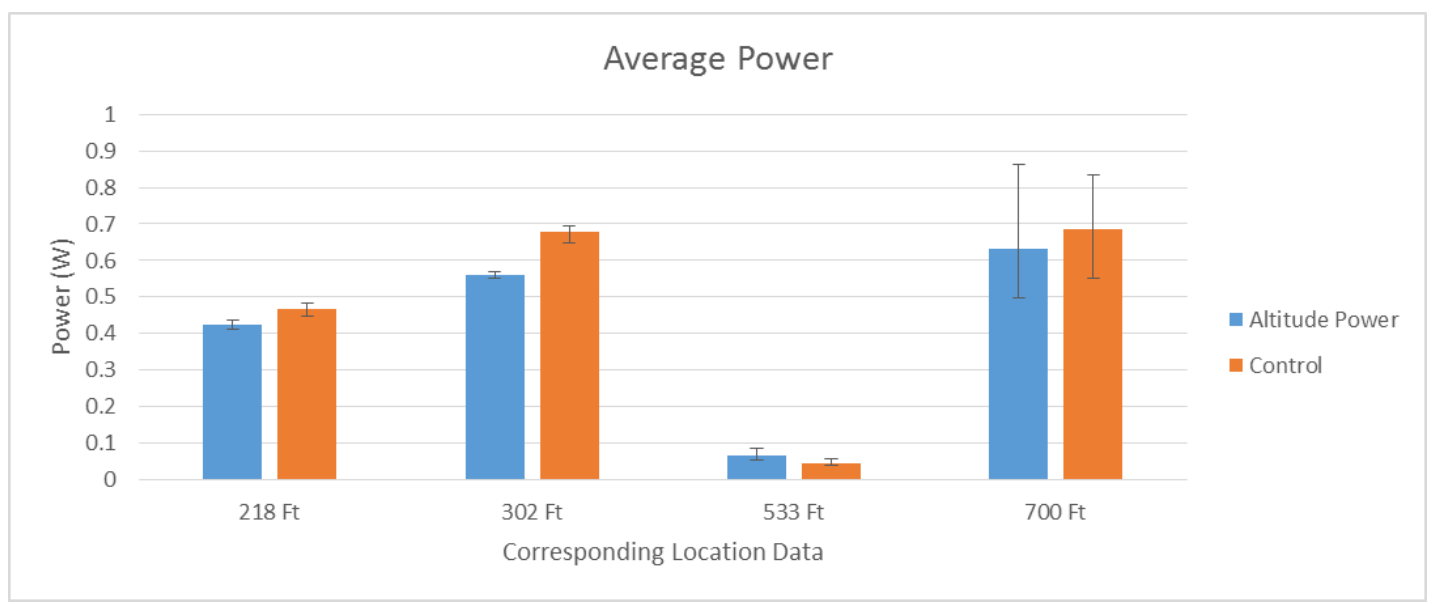

Table 1 above shows the average data collected from each altitude and the corresponding control data. The left of each group is the data from the different altitudes and right is the control. Error bars are presented as the average Max/Min of each location on the corresponding days.

The location data seen on the $\mathrm{x}$-axis refers to both the location itself and the corresponding control data (taken at the same time), with intermittent cloud interference on the $533 \mathrm{ft}$ and $700 \mathrm{ft}$ location. The data ranges from under $0.1 \mathrm{~W}$ to under $0.7 \mathrm{~W}$ and is typically higher at the ground location. Error from each location other than the 700ft location presents a fairly tightly packed data grouping. The readings would suggest a higher power output at the ground level than the various altitudes, possibly due to temperature differences. 
Table 2 below outlines lux, or the amount of ambient light per corresponding altitude.

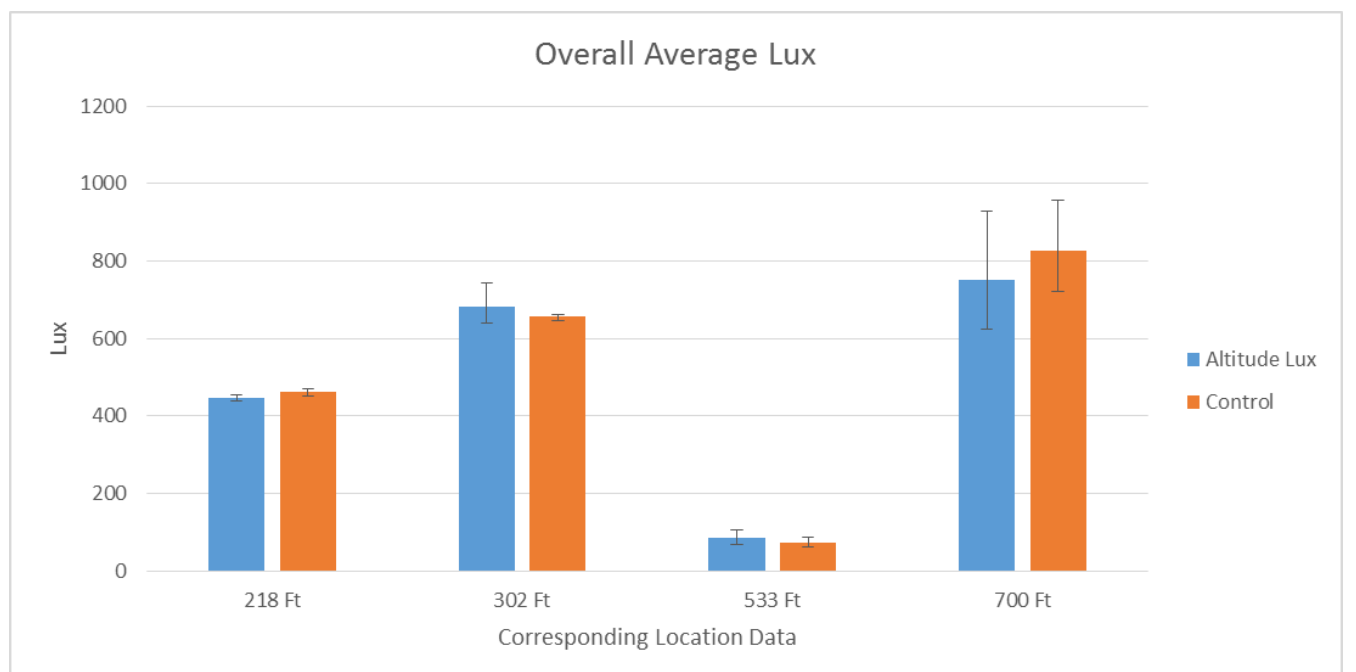

Table 2 above shows the average ambient light available from each location and the corresponding light available at the control location. The left column in each group is the data collected from the labeled altitudes and the right column is from the corresponding ground location.

lux output per altitude, with the exception of the 700ft location, remained generally constant. However, it is important to consider that the days the 700ft location data was collected had interspersed cloud cover and the amount read at the ground location was apparently randomly less covered with clouds than the 700ft building location.

As is suggested from our research, temperature is a variable that affects solar power. The temperatures seen below in Table 3 are well grouped together, but unsurprisingly slightly lower at the different altitudes when compared to the corresponding ground readings. By correcting for lux and temperature with respect to power, a closer correlation to expected levels by comparison does become apparent. 


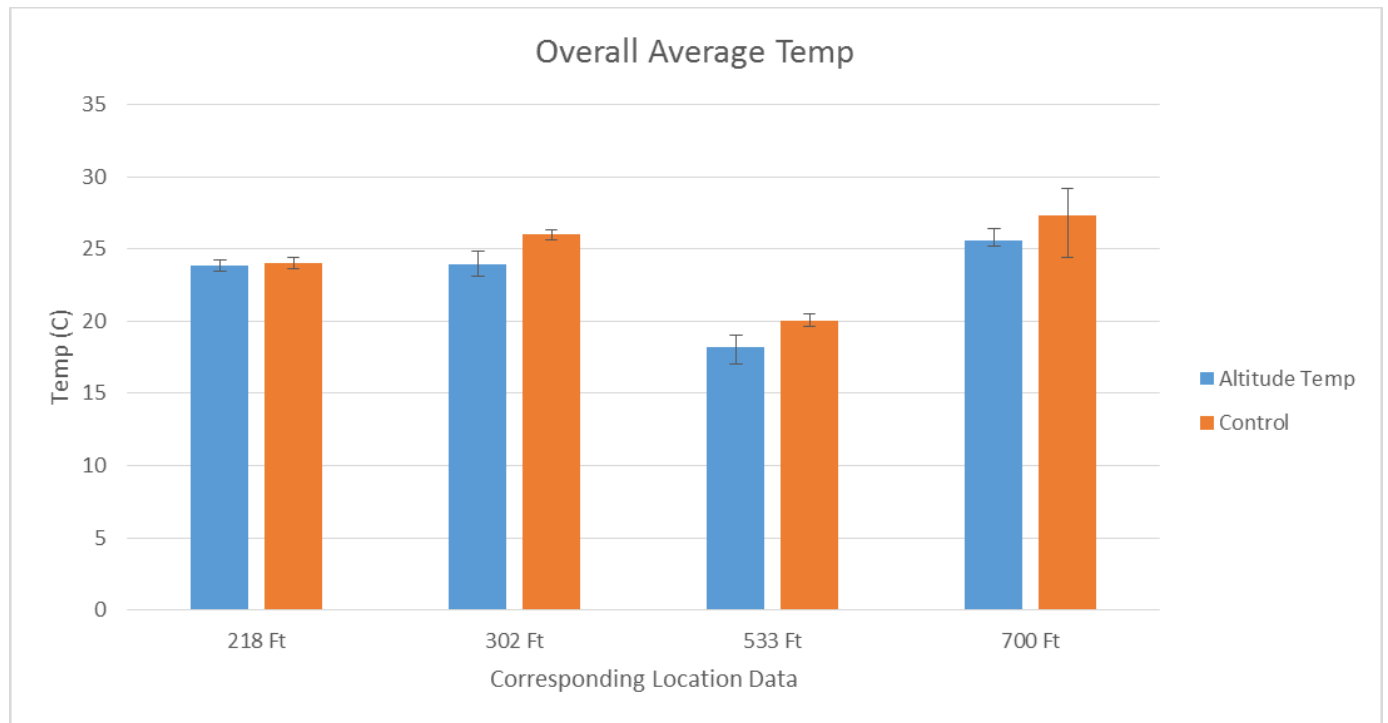

Table 3 above shows average temperature data collected from each location along with corresponding ground readings. The left column in each group is the data collected from the labeled altitudes and the right column is from the corresponding ground location.

The data collected does not yield statistically significant results. However, when factoring in both temperature and ambient light, power levels do seem to approximately follow expected trends.

Student Outcomes: The surveys received a total of eighteen responses; ten from participants and eight from non-participants. All recipients of the survey were assessed for likelihood of participating in similar projects in the future, with those already involved being the most likely (Figure 1).

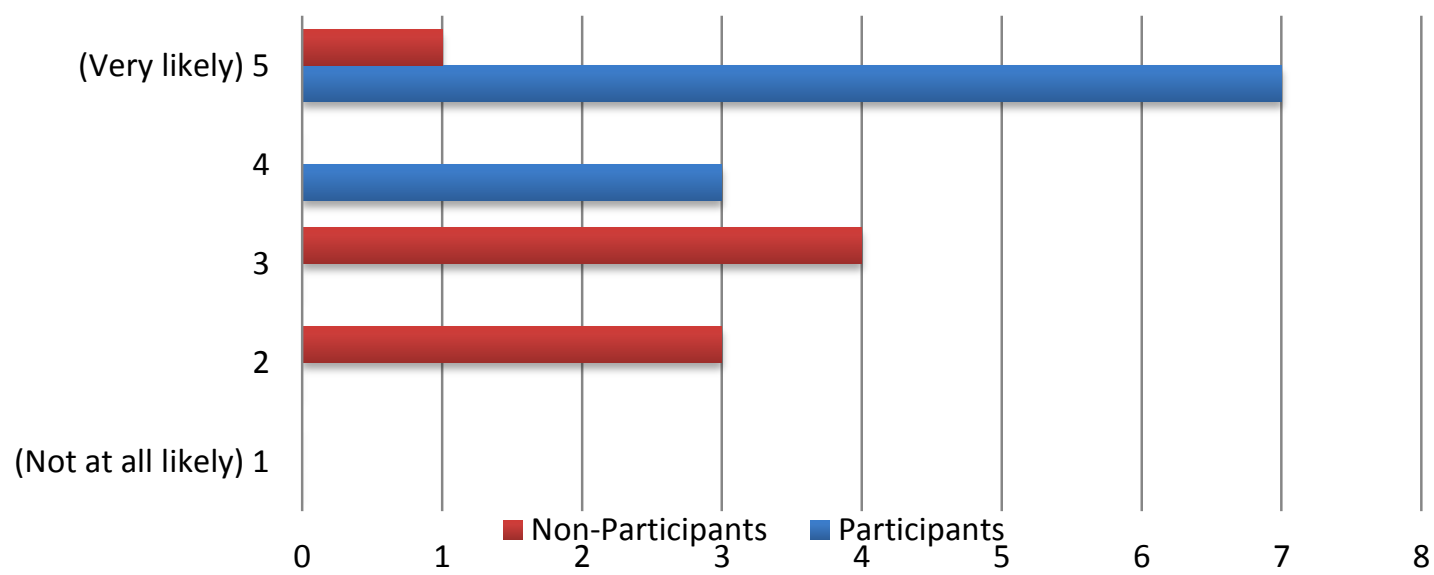

Figure 1: Survey Responses from Participants and Non-Participants when asked "How likely are you to participate in future projects similar to this one?" 
When those who did not participate were asked what factors influenced their decision not to participate in the solar energy research project, half responded that they didn't feel qualified or experienced enough (Figure 2).

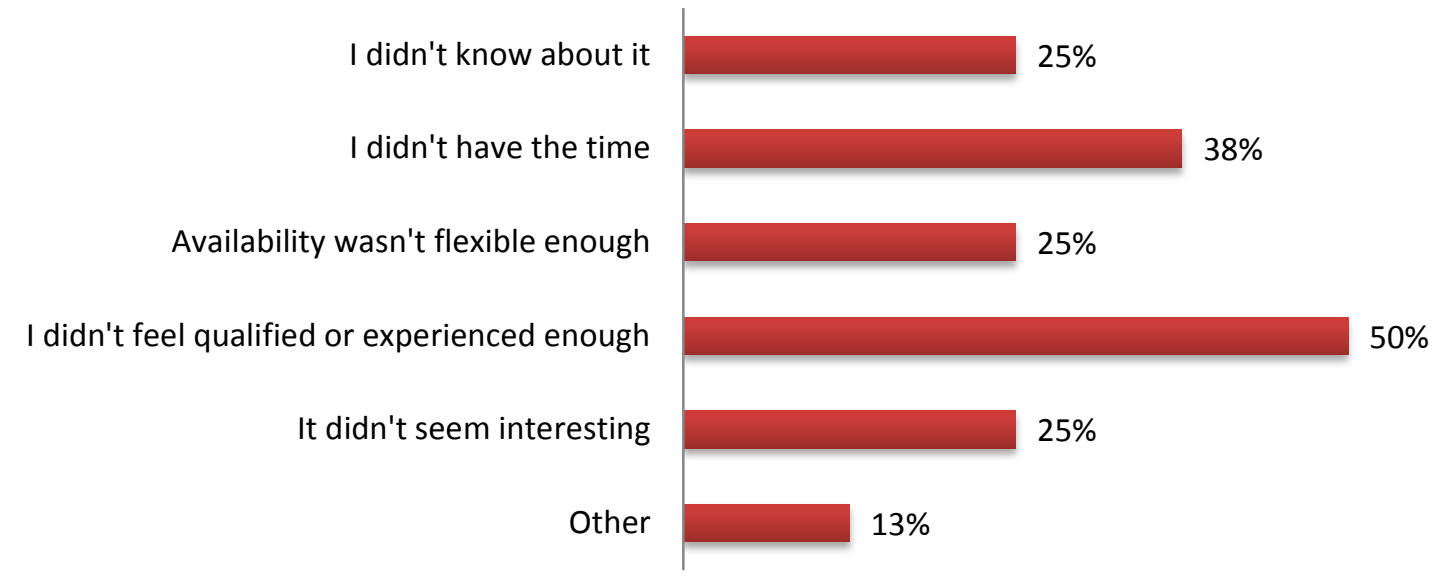

Figure 2: Survey Responses from Non-Participants when asked "What factors influenced your decision not to participate in the solar panel research project?"

When asked how they knew about the project, the majority indicated it was from another active student organization member (Figure 3).

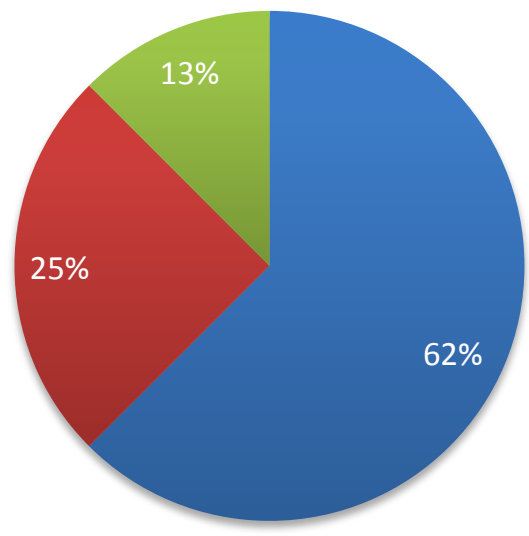

By being a student organization member

- Heard about it from a friend or classmate

Didn't know about it

Figure 3: Survey Responses from Participants and Non-Participants when asked "How did you know about this project?"

When those who participated in the project were asked in what way they took part, all ten actually helped conduct the experiment, two took part in the literature review, three in the experimental design, five with analyzing the data, and five with writing the paper (Figure 4). 


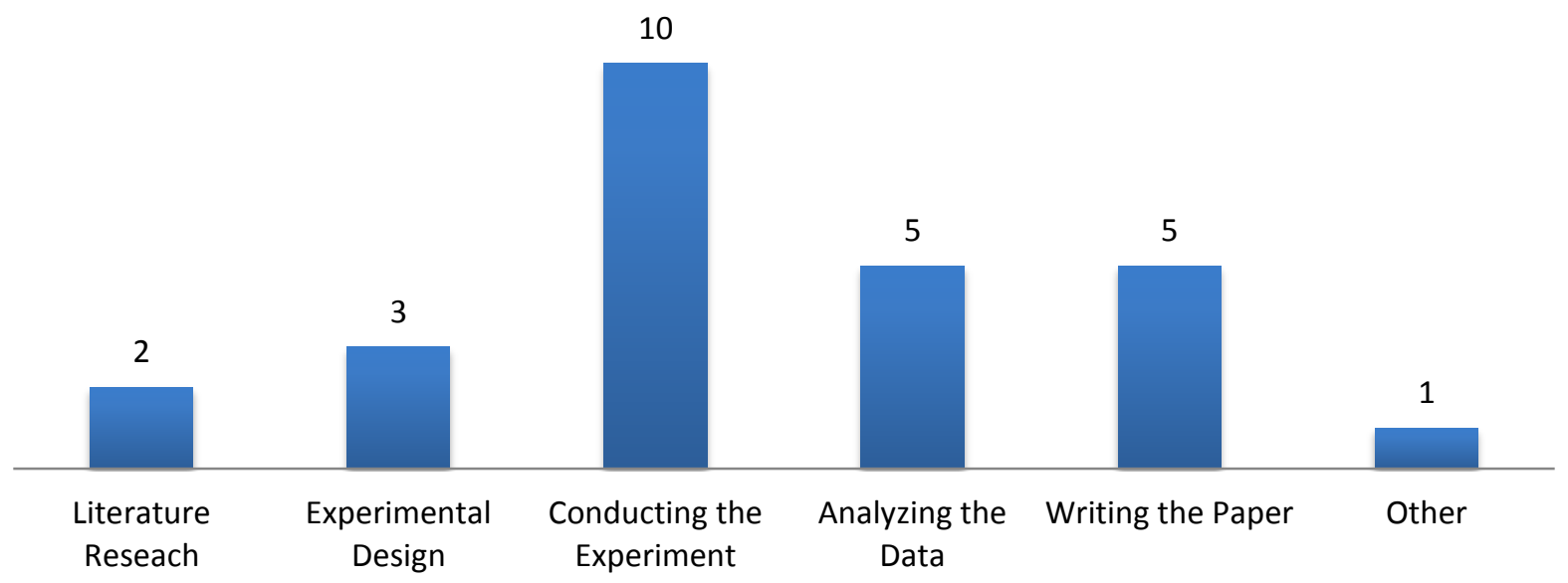

Figure 4: Survey Responses from Participants when asked, "How did you participate in the solar panel research project?"

When asked about what was gained from the experience, a large majority responded that it increased their knowledge about atmospheric effects and solar energy and gave them experience conducting an experiment, five mentioned it gave them experience conducting research, six noted it gave them experience working on a team, and eight responded that it was fun. When participants were asked which aspects of this project they found challenging, eight said that defining the best way to analyze the data was difficult, three mentioned the technical writing, and two claimed that nothing was challenging (Figure 5).

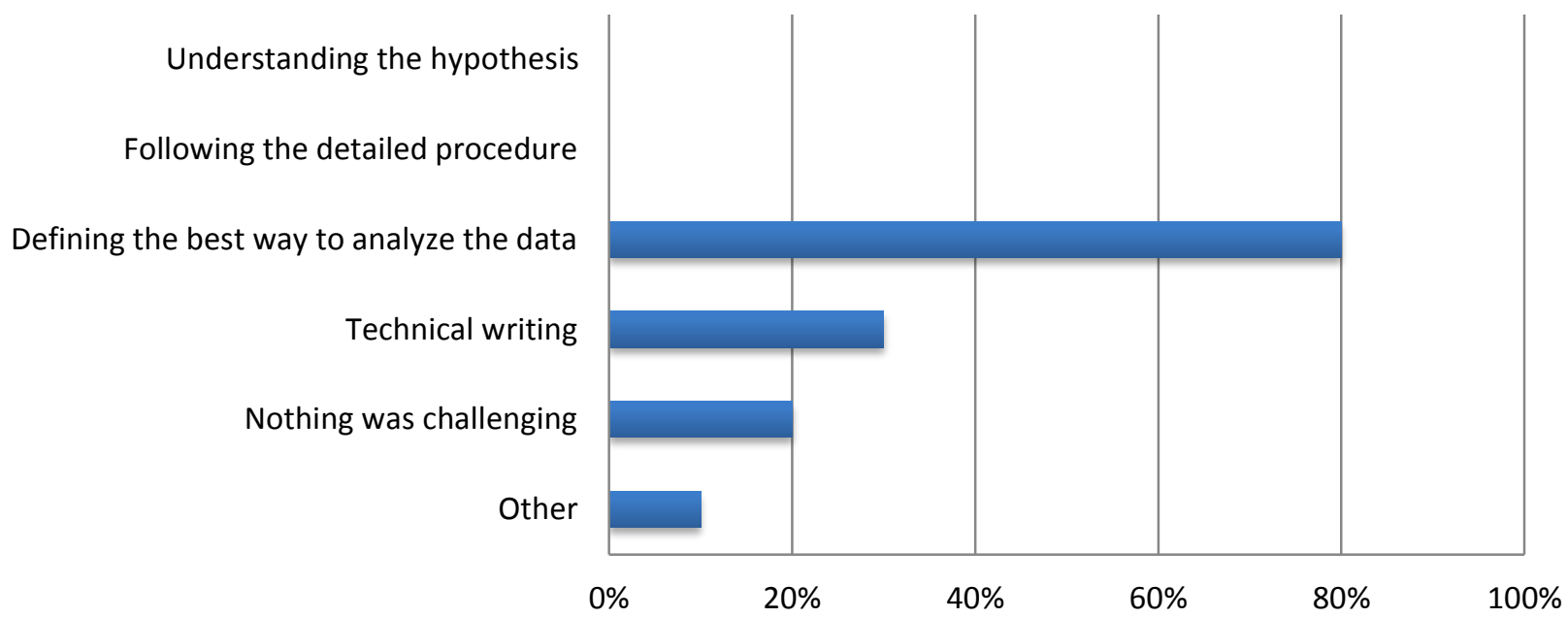

Figure 5: Survey Responses from Participants when asked, "Which aspects of this project did you find challenging?"

When participants were asked to rate the overall experience, seven rated it as "Awesome," two as "Good," one as "Neutral," and none rated as either "Somewhat Unpleasant" or "Terrible." When students were asked if the project expanded knowledge or awareness of atmospheric effects and solar energy, $10 \%$ responded that it provided a major expansion, $60 \%$ that it was a moderate expansion, and $20 \%$ replied noting a minimal expansion (Figure 6). 


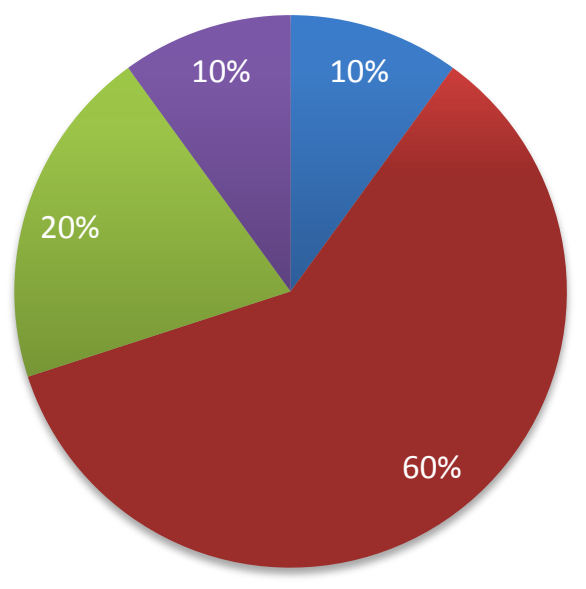

Major expansion

Moderate but clear expansion

Minimal expansion

Not at all

Figure 6: Survey Responses from Participants when asked, "Would you say this project has expanded your knowledge or awareness of atmospheric effects and solar energy?"

The participants were then asked how their attitude toward educational research had changed as a result of the project. Out of the same group, eight out of ten responded that it had a very positive impact on their attitude toward research, one reported feeling slightly more positive, and one was unaffected (Figure 7).

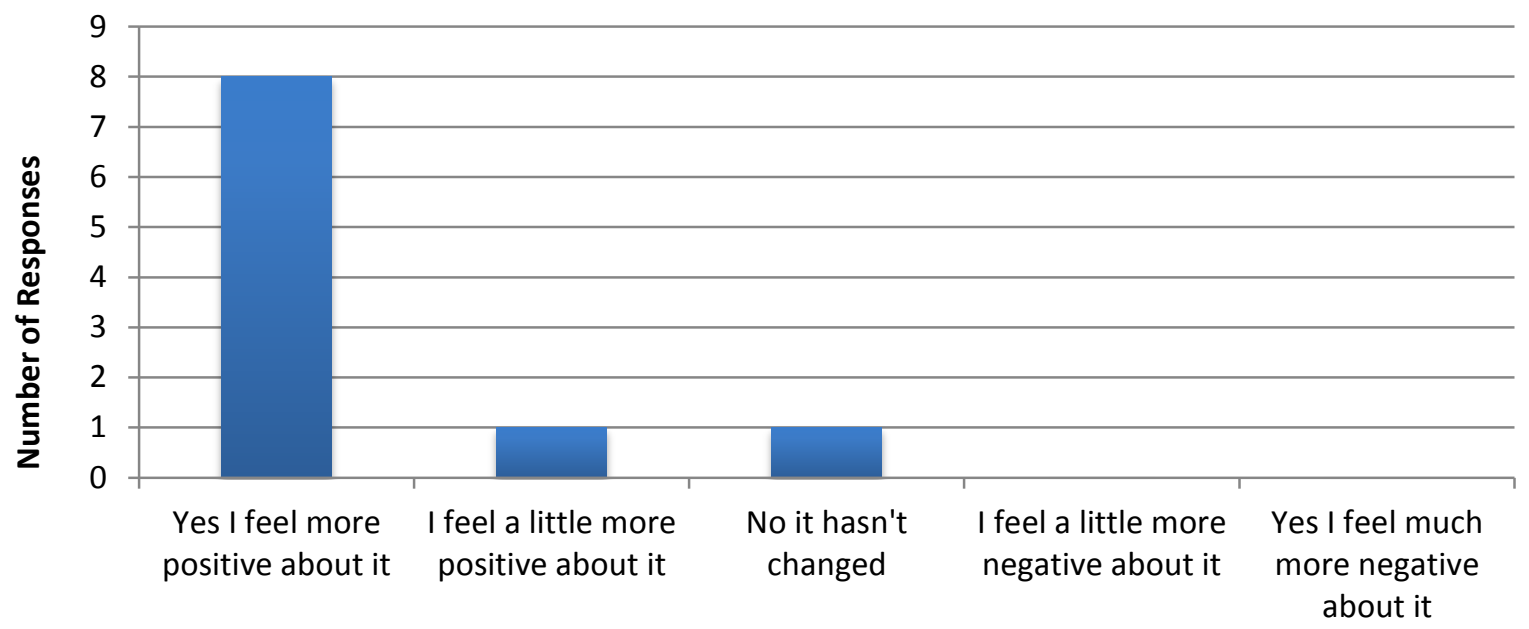

Figure 7: Survey Responses from Participants when asked, "Has your attitude towards educational research changed as a result of this experience?"

This portion of the survey suggests that students feel much more positive about educational research as a result of this study, as shown by the supporting evidence in the survey results.

\section{Discussion}


Experiment: Due to the ratio between the hypothesized effect and the error magnitude of the equipment, the research team was unable to identify an impact, which may be due to the smaller range in altitude available within the city where the tests were performed. Frequent intermittent cloud cover also induced a significant contribution to error, mostly impacting the $533 \mathrm{ft}$ and $700 \mathrm{ft}$ experimental results. The researchers theorized on some of the possible confounding variables which could have impacted the results, but which had not been measured or tested during the experiment. Accumulation of moisture and dirt/grime was not responsible for any reduction in power production, as had been the case with previous studies, due to the short experimental period used ${ }^{10}$. Another potential source was the chemical composition of the atmosphere. These substances can rank from larger particles, such as PM (particulate matter) 10 and 2.5 (classes, based on microns of diameter), to smaller molecular chemicals like ozone $\left(\mathrm{O}_{3}\right)^{9}$. Since this study was conducted in Indianapolis, the analysis should consider the possibility of non-visible atmospheric pollution. The 2010 Census ranked Indianapolis as the 12th largest city in the United States ${ }^{11}$. With this designation comes the impact of transportation and commercial atmospheric degradation. Indianapolis houses a coal power plant within its metropolitan area, as well as additional power plants and refuse incinerators on its southwest reaches. These point sources of pollution were considered for their impact, but due to the prevailing southwest winds during the study periods, it was determined their impact would have been minimal since all study locations were located upwind of the source location. Alternatively, Interstate- 65 runs through the downtown area and could have had some impact on the results. However, since the location is significantly lower in elevation than the building rooftops (approximately 100ft minimum) and not proximal to any of the study sites (more than $1 \mathrm{~km}$ ), the air pollution would likely have been diluted enough to impose only a minimal impact ${ }^{9}$.

An additional impact considered is the change in instantaneous field of view (IFOV). The control was always situated in a campus courtyard with relatively open horizons for an urban setting. The experimental altitude locations were placed on commercial roofs which have more objects proximal to the sensors' location (walls, air conditioning equipment, antennas, etc.). Depending on the location, these objects could be considered to either obstruct the IFOV of the solar panel and lux, or could potentially reduce the availability of reflected light off of nearby specular surfaces to increase available light to the systems. Although this situation was considered, the students could not come up with a way to mitigate this confounding. Therefore, no further attempt to normalize the variable, besides compensate for lux to output, was incorporated into the study. Finally, while the decreasing temperature throughout the course of the study likely had bearing on numerical outcomes, preliminary analysis suggested that factoring in the theoretical effect would not have altered the overall consensus of the data correlation.

The fact these margins of error existed in the experiment does not necessarily imply that the acquired data is invalid or speaks against the methodology. It simply speaks to the nature of the solar panels used, which fluctuated greatly within the parameters of this experiment. This is evident in the real-world challenge of transmitting solar energy from panels into electrical grids, as without certain measures taken; they often create large spikes and dips in energy that would otherwise be unsafe or unreliable. Evidence between the relationship experimentally derived between the PV current output of the solar panels and available ambient light support the soundness of the methodology attempted (Figure 5). 


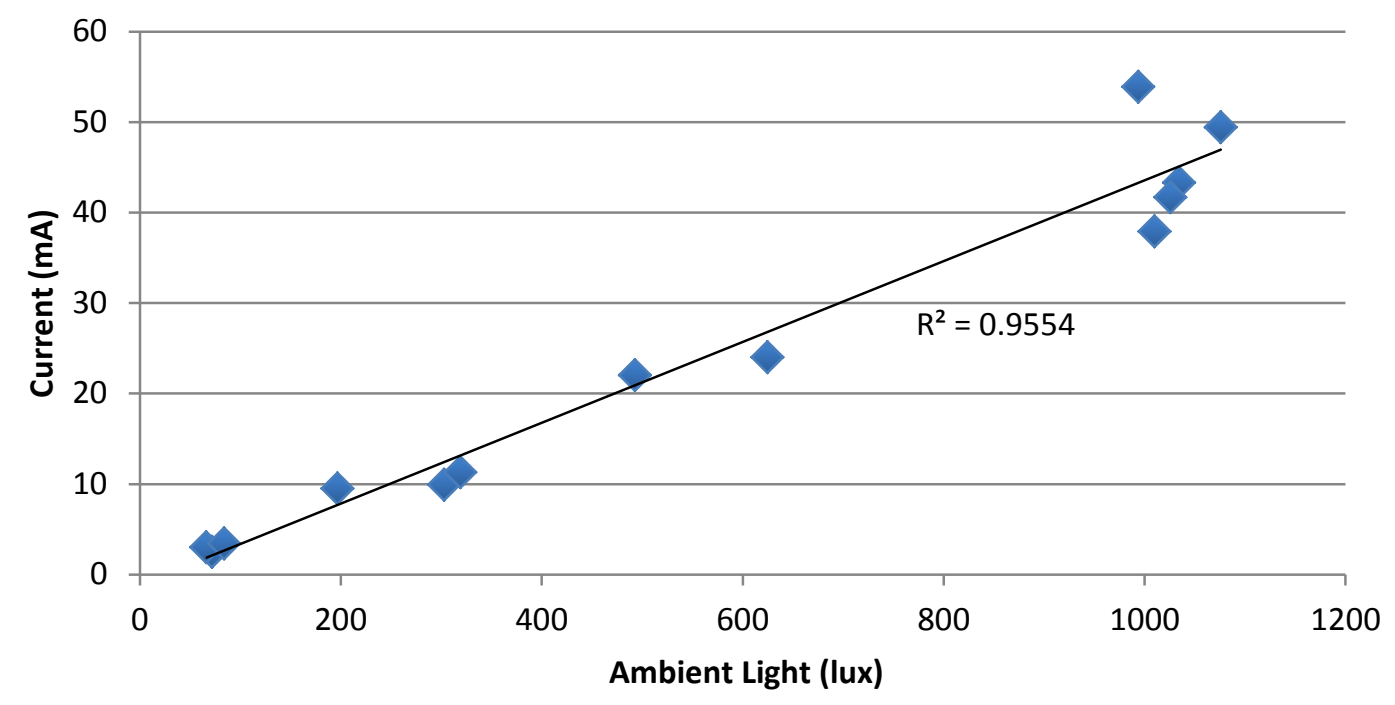

Figure 8: A plot of measured current from the solar panels vs. ambient light gives a linear relationship with an $R^{2}$ value of 0.96 , which supports known relationships between PV current and ambient light.

Because these two variables seem to positively correlate, the fact that altitude did not have enough of a measurable effect on the current and/or energy based on our data is more apparent. Any differences calculated were outweighed by the margin of error within the capabilities of our equipment. The collected data is, however, sound in terms of methodology because it correlates with the known relationship between current and ambient light in solar panels.

Student Outcomes: Overall, the responses seemed to indicate that the students who chose to participate in the research project were affected positively by the experience. Participants stated that they gained knowledge about atmospheric effects and solar energy, and experience with research, conducting an experiment, and working as a team. These are skills that can be carried on in future careers or educational endeavors. The majority of those who participated in the project felt their knowledge of atmospheric effects and solar energy was moderately but clearly expanded. As this is a vast and complicated subject, it is not expected for students to thoroughly understand all aspects of atmospheric effects after one semester. However, the students did expand their knowledge in a clear and comprehensive way, gaining a basic understanding that they can build on in the future if they so desire.

The majority of the students who participated stated that they found the data analysis to be the most challenging aspect of the study. The high number of variables taken into account during the experiment made for an overwhelming abundance of data that was difficult to sort through. This challenge drove those involved to think critically about the data and the science behind it, leading them to further develop their analytical skills and gain valuable knowledge and experience. Students who participated in the project stated that they were much more likely to participate in similar experiments in the future than those who did not participate. This suggests that the experience changed their outlook on research and experimentation, encouraging them to seek out similar projects in the future that they may not have pursued without this experience. The majority of the non-participants who took the survey are SEDS (Students for the Exploration 
and Development of Space) members, which suggests they hold similar interests to those who did participate, but chose to decline for other reasons.

Half of the students who did not participate stated that they did not feel experienced or qualified enough, which is a problem that inhibits many students from participating in undergraduate research or applying for internships or scholarships. This project was actually open to all students who were interested and participants varied in their class standings, majors, and skill levels. Since the project was meant as a learning opportunity, no students were turned away due to lack of experience or qualifications. Students were able to choose which aspects of the project to be involved in, using their individual strengths to elevate the overall effectiveness of the group. Students who participated stated that they now feel significantly more positive about educational research and experimentation after the experience. These students may now be more likely to participate in undergraduate research projects, apply for research positions, and partake in internships that could lead to higher career opportunities. Students who may have felt hesitant or intimidated by the idea of educational research and experimentation can now feel more confident about getting involved in these opportunities in the future.

Future Directions: Participating students spent many hours rigorously attempting to try and explain the research outcomes, assess what could be improved, and propose new theories to be tested in the future. Proposed improvements include the need for bigger, more powerful solar panels and more precise data collection equipment in order to induce larger and more obvious results. A yearlong study to provide a larger normalized data pool under improved weather conditions using a high-tech data logger would significantly improve results. It may also be useful to simultaneously run a detailed particulate matter analysis alongside each experiment and compare the outcomes. Running the experiments during a more closely spaced time period would also have prevented any significant changes in the angle of the sun, which may partially justify larger errors arising near the end of the study. Lastly, an improved light gathering device which could factor out light attenuation laterally from surrounding buildings on rooftops could improve the assessment of power-per-lux photovoltaic output.

\section{Conclusion}

Solar energy is quickly becoming a more popular option for clean energy, but its efficiency in urban environments is largely understudied. Increased particle pollution in urban atmospheres potentially limits photovoltaic efficacy both in accumulated grime and also in atmospheric scatter of insolation energy. The objective of this study was to simultaneously measure photovoltaic power output near solar noon at multiple heights within a city environment to determine the influence of altitude on power output between $200 \mathrm{ft}$ and $800 \mathrm{ft}$ versus a relative control (0ft). Meteorological conditions were taken into consideration to reduce confounding errors. With emphasis on the educational aspect of the learning experience, surveyed students affiliated with the project demonstrated an overall positive experience and change in outlook towards scientific research. Students who chose not to participate were also surveyed to provide a control group.

The effect of altitude is found to be minimal within the parameters of this study, as analysis of our data did not significantly demonstrate an improvement in solar productivity at increased altitudes. However, the rigorous test methodology developed provides a means for quantitative analysis in cities with greater levels of pollution relative to the city tested. Student 
surveys overall indicated a positive correlation between participation in the project and the amount learned in the process. New insight on solar panel efficacy in cities is provided, with the hope that similar research designs will continue to encourage students to go beyond minimal coursework during their education and become successful leaders of tomorrow.

\section{Bibliography:}

[1] Smil, V. "21st century energy: Some sobering thoughts." OECD Observer (2006): 258/59:22-23.

[2] Environment America. "At the Forefront of America's Solar Energy Revolution." Shining Cities (2014): 12-24.

[3] Panjwani, Manoj. "Effect of Altitude on the Efficiency of Solar Panel." International Journal of Engineering Research and General Science (2014): 461-464.

[4] EPA - United States Environmental Protection Agency. Heat Island Effect [Online]. Retrieved from: http://www.epa.gov/heatisland.

[5] Honsberg, Christiana and Stuart Bowden. Effect of Temperature [Online]. Retrieved from: http://pveducation.org/pvcdrom/solar-cell-operation/effect-of-temperature.

[6] Kaldellis, J. K., and M. Kapsali. "Simulating the dust effect on the energy performance of photovoltaic generators based on experimental measurements." Energy 36.8 (2011): 5154-5161.

[7] Mekhilef, S., R. Saidur, and M. Kamalisarvestani. "Effect of dust, humidity and air velocity on efficiency of photovoltaic cells." Renewable and Sustainable Energy Reviews 16.5 (2012): 2920-2925.

[8] Mani, Monto, and Rohit Pillai. "Impact of dust on solar photovoltaic (PV) performance: research status, challenges and recommendations." Renewable and Sustainable Energy Reviews 14.9 (2010): 3124-3131.

[9] IDEM - Indiana Department of Environmental Management. Air Quality in Indiana [Online]. Retrieved from: http://www.in.gov/idem/airquality/index.htm.

[10] Jiang, Hai, Lin Lu, and Ke Sun. "Experimental investigation of the impact of airborne dust deposition on the performance of solar photovoltaic (PV) modules." Atmospheric Environment 45.25 (2011): 4299-4304.

[11] United States Census Bureau. 2010 Census [Online]. Retrieved: www.census.gov/dataviz/vizualizations/007/508.php 